\title{
Editorial
}

\section{Pre-Notifications, Preliminary Investigations, and the Rights of Third Parties in State Aid Procedures - Beware of the Black Hole!}

The persistently cautious approach of the Court of Justice of the European Union (CJEU) to recognising any meaningful rights for third parties in state aid proceedings before the European Commission as well as in judicial proceedings is well-known and frequently criticised. With the recent adoption of the new Climate Law at the end of June and the official launch of 12 new legislative proposals on 14 July 2021, the EU institutions are rolling out the apparatus to realise the objectives of the 'Green Deal'. One of those objectives is to guarantee greater stakeholder participation in decision making at national as well as European level. The public must buy in to the ambitions of the green transition if the European Union's objectives are to be embraced. It therefore must have a voice in the process and, one would hope, that voice should be heard particularly in EU competition proceedings such as State aid investigations, where important societal and economic interests are at stake. The competition rules cannot fall short and fail to do justice to the interests of the very parties at the heart of the new climate legislative impetus.

\section{The CEEAG and Public Consultation}

The newly published draft guidelines for State aid for climate, environment protection and energy (CEEAG) opened for consultation up to 2 August 2021. ${ }^{2}$ Reflecting the Green Deal commitments, the draft introduces new requirements for public consultation. For example, in accordance with section 4 (Categories of Aid - Aid for the reduction and removal of greenhouse gas emissions through support for renewable energy), prior to notification Member States must consult publicly on measures to be notified under this section. Similar requirements are proposed for State aid measures for the security of electricity supply. Consultation questionnaires must be drawn up in accordance with the rules proposed in the draft guidelines (see, for example, at point 85 ). Member States must publish a response to the consultation - explaining how the possible negative impacts on competition have been minimised through the scope or eligibility of the proposed measures. They must provide a link to their response as part of the notification of State aid for the support of renewable energy or to promote security of electricity supply.

The duty of public consultation - if approved in the definitive version of the guidelines - is an important innovation. It is so far unique to the draft CEEAG. Although the guidance on how the consultation procedure is to be designed at national level is not especially prescriptive, it will be interesting to see how the results of the (proposed) consultation exercises are absorbed into the current procedural framework for the assessment of the compatibility of notified State aid. Unless more attention is paid to this aspect, the assimilation process may prove to be com-

1 Council of the EU, 'Council adopts European climate law' (Press release, 28 June 2021) <https://www.consilium.europa.eu/en/press/press -releases/2021/06/28/council-adopts-european-climate-law/> and European Parliament, 'EU Climate Law: MEPs confirm deal on climate neutrality by 2050' (Press release, 24 June 2021) <https://www.europarl.europa.eu/news/en/press-room/20210621IPR06627/eu-climate -law-meps-confirm-deal-on-climate-neutrality-by-2050> accessed 3 September 2021.

2 European Commission, DG Competition, 'Public consultation on the revised Climate, Energy and Environmental Aid Guidelines (CEEAG)' https://ec.europa.eu/competition-policy/public-consultations/2021-ceeag_en accessed 3 September 2021. 
plex and the result not necessarily encouraging for third parties who have gone to the effort of responding to the consultation. The CJEU, inevitably, will be called upon to shed further light on how this new consultation process - if adopted - is to be fitted into the current informal and formal stages of the State aid clearance procedures before the European Commission.

\section{The Tempus Energy Case - Some Serious Difficulties Ahead?}

In fact, we may not need to wait until the new CEEAG are adopted to see how these new consultation rights may fit in to the existing procedures. The Tempus case (C-57/19P) already presents the CJEU with the opportunity to clarify many of these issues. Unfortunately Advocate General (AG) Tanchev's Opinion of 3 June $2021^{3}$ in the Tempus case does little to clarify the links between the different procedural stages and the rights of third parties in relation to these stages. Nevertheless, it should be recalled that on one aspect the CJEU's case law is relatively clear: if the European Commission has 'doubts' (or faces 'serious difficulties') at the conclusion of the preliminary investigation it must initiate the formal investigation procedures provided for in Article 108(2) TFEU in order to protect third party rights and, ultimately, to put the European Commission in the proper position to decide, being fully informed of the matter.

On 15 November $2018^{4}$, the General Court (GC) upheld Tempus' action. The GC had applied the established case law, which it recalled at paragraph 67 of its ruling. ${ }^{5}$ It held that the European Commission had not properly dealt with the information submitted to it by third parties such as Tempus at the pre-notification stage and the issues surrounding the status of demand side response (DSR) in the GB capacity market (see paragraphs 107 - to 109 GC). At the time of the notification, Tempus was also engaged in DSR services in the UK. This type of service - which was then relatively novel - helps customers to shift their electricity demand to periods when prices are low. In its $2014 \mathrm{EEAG}^{6}$ the European Commission encourages Member States to promote DSR as an efficient alternative to building new (often gas-fired) electricity capacity. ${ }^{7}$ The new draft CEEAG continues this approach (see point 299).

As the GC observed:

The fundamental objective of the capacity market was to encourage capacity providers, that is to say, principally, both electricity generators (power plants, including those using fossil fuels) and DSR operators, who offer a service whereby consumption is rescheduled or reduced, to take into account the difficulties that may arise during high-demand periods. Thus,

\footnotetext{
Case C-57/19 P European Commission v Tempus Energy [2021] ECLI:EU:C:2021:451, Opinion of AG Tanchev.

Case T-793/14 Tempus Energy v Commission [2018] ECLI:EU:T:2018:790.

pt 67: ' ... Tempus bears the burden of proof, which it can discharge by reference to a body of consistent indications, concerning, first, the circumstances and the length of the preliminary examination procedure and, second, the content of the contested decision (see, to that effect, judgment of 10 February 2009, Deutsche Post and DHL International v Commission, T-388/03, EU:T:2009:30, paragraph 93). In particular, the insufficient or incomplete nature of the examination carried out by the Commission during the preliminary examination procedure constitutes an indication of the existence of doubts within the meaning of Article 4 of Regulation No 659/1999 (see judgment of 10 July 2012, Smurfit Kappa Group v Commission, T-304/08, EU:T:2012:351, paragraph 81 and the case-law cited). As an interested party, Tempus has neither powers of investigation nor, in principle, investigatory capabilities that are comparable to those enjoyed by the Commission, which can, where necessary, request the cooperation of a Member State in order to complete its examination of the notified measure.'

6 OJ 2014 C200/1.

7 pt 3.9.2: 'Need for State intervention', the Guidelines provide that, in its assessment of the elements provided by the relevant State, the Commission is to take account of, inter alia, the "assessment of the impact of demand-side participation, including a description of measures to encourage demand side management'.
} 
even if they intervene at different levels - supply for generation, demand for consumption - generators and DSR operators are essential elements for the structure and functioning of the capacity market envisaged by the United Kingdom. ${ }^{8}$

\section{A Closer Look at the Role of Consultation in the Tempus Case}

- The Tempus case concerns a support scheme for capacity remuneration mechanisms in the GB electricity sector. The scheme was notified to the European Commission by the UK in 2014 and well prior to Brexit. That notification was preceded by an extensive period of consultation within the UK on the design of the system (although the cost recovery methodology underlying the scheme had actually been changed only after the national consultation had already been closed ${ }^{9}$ ). The General Court had rightly pointed out that a national consultation cannot be considered an equivalent to submissions the Commission could receive from third parties in a formal investigation procedure. ${ }^{10}$

- The Tempus case was also preceded by a lengthy pre-notification period. It may be recalled that the pre-notification phase, which arose as a result of the Commission's experience in conducting State aid control proceedings, was established in its soft law Best Practices Code. ${ }^{11}$ It is not recognized in the 'Procedural Regulation. ${ }^{.12}$

Tempus argued before the GC that the European Commission could not conclude, following a preliminary examination (lasting one month only) and in the light of the information available at the time when the contested decision was adopted, that the capacity market envisaged did not raise doubts as to its compatibility with the internal market. Indeed, during the pre-notification period and again, as soon as the preliminary examination started following the formal notification, Tempus and several other parties voiced concerns about the compatibility of the scheme with EU State aid rules. In particular, the submission by Tempus and a number of other DSR operators argued that the draft notified GB capacity market privileged generation over DSR in a discriminatory and disproportionate manner. ${ }^{13}$

Tempus explained why various aspects of the design of the GB capacity market that should have give risen to doubts within the meaning given to that concept in Article 4 of the Procedural Regulation. The European Commission directed further questions inter alia concerning DSR to the UK prior to the preliminary examination but concluded the latter stage one month later.

8 GC judgment, pt 55.

9 T-793/14 Tempus Energy, para 206: 'In the second place, it is apparent from the notification that the United Kingdom amended the cost recovery method after the public consultation. It was initially envisaged that the amount of the charges would be calculated on the basis of the electricity suppliers' market share in the electricity demand registered during the so-called 'triad' periods, that is to say the three half-hour periods registering the highest annual electricity consumption in the United Kingdom during the period from November to February (paragraphs 521 and 522 of the notification). It was only after the public consultation that the United Kingdom decided to amend the cost recovery method to adopt one based on electricity consumption between 16.00 and 19.00 during winter weekdays, as described in paragraph 200 above.'

10 See para 100, discussed below.

11 This code relates to the conduct of State aid control proceedings, and was adopted by the Commission on 16 June 2009 (OJ C 136/13; 'the Best Practices Code').

12 Regulation 2015/1589.

13 Whereas the European Green Deal also strives to deliver 'Clean energy and cutting edge technological innovation' and yet here we have the Commission (and an AG at the CJEU) ignoring the competition concerns of the trade association representing that innovation sector. 
The question raised by this situation was in fact whether a notifying Member State can postpone, in agreement with the European Commission, the objective time justifying the lodging of a formal notification (which should trigger the preliminary examination of the compatibility assessment of the notified measure) until the time they consider having solved all possible issues 'behind the scenes'. The notification is transformed into a mere formal endorsement of an informal agreement with the European Commission. The two-month deadline dedicated by the EU case law since the mid-7os (and the Procedural Regulation since its first adoption in 1999) to the preliminary examination (following a 'complete' notification) then becomes moot.

The GC annulled the decision given the length and circumstances of the pre-notification phase which lasted over one year, as well as the incomplete and insufficient content of the decision owing to the lack of an appropriate investigation during the preliminary examination, into a novel type of market design. The factors should have caused the European Commission to have doubts. It should have therefore initiated the formal investigation procedure. This would have given third parties the right to a formal consultation that is only factored into that stage of the State aid procedure.

Notably, at paragraph 100 the GC stated that

In that regard, it cannot be held [...], that a national consultation can be treated in the same way as a procedure allowing the interested parties to submit their observations, as would have been the case if the Commission had initiated the formal investigation procedure. In the context of State aid control proceedings, the relevant Member State providing the aid cannot substitute itself for the Commission, which must, [...] examine all projects intending to establish schemes of aid. It is for the Commission, rather than the Member State, where relevant and in the context of the procedure envisaged to that end, to gather all information necessary to allow it to assess the compatibility of the aid. Further, it is to the Commission, rather than to the Member State intending to provide the aid, that the interested parties must submit their observations, if they consider it necessary, in order to allow the Commission to come to a decision with full knowledge of the facts.

In other words, the European Commission should have carried out its own, formal investigation. ${ }^{14}$ The CJEU's judgment on the Tempus case may still have a bearing on cases pending before the GC on the Polish ${ }^{15}$ and Italian ${ }^{16}$ capacity mechanisms.

\section{The Advocate General's Opinion}

The AG takes a different, and excessively formalistic approach to the rights of third parties although he does recognise that spontaneous third-party observations made at the pre-notifi-

14 Meanwhile, the Commission had opened a formal investigation procedure in early 2019 (see $<$ https://bit.ly/2YAOgw5>), finding, on 24 October 2019 (see < https://bit.ly/3h7hgBR $>$ ), that the capacity mechanism was compatible with the internal market. In fact, the Commission took into account a number of voluntary commitments by the UK to amend the scheme to the benefit of DSR in a number of respects. See Commission Decision C(2019) 7610 final of 24 October 2019, recitals 277, 284, 289, 293, 296, 312, 329, 335, 340, 344 and 348. That decision has not been challenged (because, as we know, third parties trying to challenge a final decision adopted following the formal investigation procedure, face almost unsurmountable legal obstacles).

15 Action brought on 14 March 2019 - Tempus Energy Germany and T Energy Sweden/Commission (Case T-167/19) <https://bit.ly/3kYGYcT> accessed 3 September 2021.

16 Action brought on 15 November 2019 — Tirreno Power v Commission (Case T-793/19) <https://bit.ly/3h82Dhx> accessed 3 September 2021. 
cation stage can in some circumstances give rise to a duty to investigate. His Opinion concludes, in paragraph 96, that in a preliminary investigation, the Commission may in general limit itself to relying on the information contained in the Member State's notification, unless a third party provides evidence that the Commission considers to call that information into question. In the latter case, the Commission is, in the AG's view, only obliged to take account of that evidence, but does not have to go beyond the examination of the facts and points of law that the third party raised.

AG Tanchev first opined that in the course of a formal investigation and of a preliminary examination of an aid measure, the Commission has to, for the sake of sound administration and for honouring the TFEU's State aid rules, conduct a diligent and impartial examination of the measures in question, in order to dispose, when taking its State aid decision, of the most complete and reliable information possible (paragraph 80). However, in his view it suffices that the Commission examines diligently and impartially the facts and points of law brought to its attention by the Member State concerned, without being required to investigate on its own motion the circumstances of the case (paragraph 81). But as third parties have no procedural right to submit observations on an aid measure during the pre-notification as well as the preliminary examination phase, the European Commission, in turn, does not have any general obligation to take 'spontaneous observations' into account (paragraphs 84, 89, 91); this may be otherwise when evidence brought by a third party calls into question the information provided by the Member State as regards its completeness and reliability (para 93); nevertheless, the European Commission cannot be obliged, opines the AG, to investigate the case on its own motion, nor to go beyond the examination of the facts and points of law brought to its attention by the third party (paragraphs $81,85,89,96$ ).

As observed by other commentators,

the Opinion ends up leaving all discretion to the Commission to decide when to take account of third parties' observations and when it considers them substantiated enough to be worth analysing, whereas the notion of doubts, or serious difficulties, under Article 108(2) TFEU is objective. ${ }^{17}$

It is perhaps ironic that given the aspirations of the Green Deal to promote clean energy and cutting edge technological innovation, that the AG considers that the Commission could ignore the competition concerns of the trade association representing that innovative sector.

It is to be hoped that the CJEU will resolve the confusion sewn by the Advocate General when it hands down its ruling on the case on 2 September. If stakeholders' participation is to be encouraged, their input must be properly taken on board in State aid procedures. It is vital to ensure that if that input leads to objective doubts that the European Commission should have as to the compatibility of a notified State aid measure, then a formal investigation procedure should be initiated.

The Tempus case gives the CJEU an important opportunity to rule on these very issues and provide clear guidance for fair procedures, and, even more importantly, procedures allowing the European Commission to adopt better decisions.

17 See Juliette Delarue, 'How to grant unfettered discretion to the Commission to disregard third parties' submissions in State aid cases - AG Tanchev Opinion of 3 June 2021 in Tempus' (European Law Blog, 28 July 2021) <https://europeanlawblog.eu/2021/07/28/how-to -grant-unfettered-discretion-to-the-commission-to-disregard-third-parties-submissions-in-state-aid-cases-ag-tanchev-opinion-of-3-june-2021-in -tempus/> accessed 3 September 2021. 
If the CJEU does not act, the absence of any real duty on the European Commission to take into account third parties' 'spontaneous observations' (or even to proceed to some investigation on its own motion where required by the lack of information provided by the Member State concerned) could emerge as a significant gap in the existing procedure if the CJEU endorses AG Tanchev's Opinion. Instead of affirming more inclusive consultation procedures, there is a serious risk that the Tempus judgment only confirms that State aid procedures are nothing more than a black hole into which the results of the newly mandated public consultations are likely to fall. That does not augur well for the much-claimed emphasis on the 'just transition' to a greener economy with no one left behind.

\section{Postscript}

The CJEU gave its judgment on 2 September $2021^{18}$. It has largely followed the Opinion discussed in this editorial. This is to be regretted. It can be argued that what the CJEU expects from 'interested parties' in State aid procedures is wholly inconsistent with the fact that in the pre-notification procedure remains secret and is not accessible to third parties ${ }^{19}$. Yet the Court states at paragraph 164 that: 'It is not apparent from the judgment under appeal that that statement by the United Kingdom was challenged in the observations submitted spontaneously to the Commission.' This is asking the impossible because the interested parties had no access to the UK's notification and did not know about the UK's statements to the Commission and so could not challenge them.

The preliminary examination phase is of course not that different from the third parties' point of view - again there is no access to information and no possibility to raise issues in respect of that information. The energy transition has to face up to the reality of a considerable inequality of arms across parties. That is why meaningful consultation is important. Yet the Tempus judgment gives Member States a broad discretion to state what they want, and the Commission will not be required to check and endorse that information in the absence of contrary evidence brought by third parties who remain precluded procedurally from bringing such evidence properly before the Commission in the first place.

Leigh Hancher*

8 Case C-57/19 P Commission v Tempus energy and Tempus Energy Technology [2021] ECLI:EU:C:2021:663

19 ibid, eg in paras 40, 86, 119, 122, 129, 130.

* Leigh Hancher, Professor of European Law, University of Tilburg, The Netherlands; part-time Professor, Florence School of Regulation (FSR), European University Institute, Italy; Director, FSR Energy Union Law Area. For correspondence: <I.L.Hancher@tilburguniversity.edu>. 